\title{
Mechanical overload decreases tenogenic differentiation compared to physiological load in bioartificial tendons
}

\author{
Stefan Pentzold ${ }^{*}$ and Britt Wildemann
}

\begin{abstract}
Background: Tenocytes as specialised fibroblasts and inherent cells of tendons require mechanical load for their homeostasis. However, how mechanical overload compared to physiological load impacts on the tenogenic differentiation potential of fibroblasts is largely unknown.

Methods: Three-dimensional bioartificial tendons (BATs) seeded with murine fibroblasts (cell line C3H10T1/2) were subjected to uniaxial sinusoidal elongation at either overload conditions $(0-16 \%, \varnothing 8 \%)$ or physiological load $(0-8 \%$, $\varnothing 4 \%$ ). This regime was applied for $2 \mathrm{~h}$ a day at $0.1 \mathrm{~Hz}$ for 7 days. Controls were unloaded, but under static tension.

Results: Cell survival did not differ among overload, physiological load and control BATs. However, gene expression of tenogenic and extra-cellular matrix markers (Scx, Mkx, Tnmd, Col1a1 and Col3a1) was significantly decreased in overload versus physiological load and controls, respectively. In contrast, Mmp3 was significantly increased at overload compared to physiological load, and significantly decreased under physiological load compared to controls. Mkx and Tnmd were significantly increased in BATs subjected to physiological load compared to controls. Proinflammatory interleukin-6 showed increased protein levels comparing load (both over and physiological) versus unloaded controls. Alignment of the cytoskeleton in strain direction was decreased in overload compared to physiological load, while other parameters such as nuclear area, roundness or cell density were less affected.

Conclusions: Mechanical overload decreases tenogenic differentiation and increases ECM remodelling/ inflammation in 3D-stimulated fibroblasts, whereas physiological load may induce opposite effects.
\end{abstract}

Keywords: Tenogenesis, Gene expression, Cytoskeleton, Mechanical strain, Inflammation, C3H10T1/2

\section{Introduction}

Tendons connect force-generating muscles to bones to enable motion of humans and animals. Therefore, tendons and their inherent cells such as tenocytes as specialised fibroblasts are naturally under mechanical load. This force is essential for the homeostasis of tenocytes and whole tendons, but only a certain range of loading enhances net matrix production and thus tissue repair

\footnotetext{
* Correspondence: stefan.pentzold@med.uni-jena.de

Experimental Trauma Surgery, Department of Trauma, Hand and Reconstructive Surgery, Jena University Hospital, Friedrich Schiller University Jena, Am Klinikum 1, 07747 Jena, Germany
}

[1]. Whereas physiological relevant load in terms of elongation has important implications for the development and repair of tendons, overload and/or overuse can cause tendon impairments and injuries $[2,3]$. Acute and chronic tendon injuries like tendinopathies occur frequently not only among older, less active and overweight persons, but also young, active persons and athletes are affected [4]. Moreover, tendons have limited self-healing capacity and current treatments (e.g. ultrasound, corticosteroids injection, surgery) have many limitations [1]. Therefore, distinguishing overload as a pathological condition from physiological and thus

(c) The Author(s). 2022 Open Access This article is licensed under a Creative Commons Attribution 4.0 International License, which permits use, sharing, adaptation, distribution and reproduction in any medium or format, as long as you give appropriate credit to the original author(s) and the source, provide a link to the Creative Commons licence, and indicate if changes were made. The images or other third party material in this article are included in the article's Creative Commons licence, unless indicated otherwise in a credit line to the material. If material is not included in the article's Creative Commons licence and your intended use is not permitted by statutory regulation or exceeds the permitted use, you will need to obtain permission directly from the copyright holder. To view a copy of this licence, visit http://creativecommons.org/licenses/by/4.0/ The Creative Commons Public Domain Dedication waiver (http://creativecommons.org/publicdomain/zero/1.0/) applies to the data made available in this article, unless otherwise stated in a credit line to the data. 
beneficial load would optimise loading regimes which could finally improve existing rehabilitation programs and help to engineer improved tendon constructs.

Strategies to induce the tenogenic differentiation potential of cells involves the application of mechanical strain mainly from 1 to $12 \%$ [1], which is imposed on individual cells or whole tissues, among other treatments such as growth factor supply and various scaffold surface structures [5-7]. However, conditions for overload or physiological load often vary among cell types and loading systems [8]. Similarly, the precise level (magnitude, frequency, duration) of stimulation required for normal tendon homeostasis in vivo often remains unknown [9]. For example, 9\% cyclic strain (at $0.25 \mathrm{~Hz}$ ) can cause damage to cells compared to $6 \%$ and $3 \%$ strain using Achilles tendons cultured ex vivo in growth medium [3]. Mechanical overloading at $12 \%$ strain of human tenocytes was shown to result in disruption of the cytoskeleton in a time-dependent manner [10]. Similar to overload unloading leads to increased cell apoptosis and collagen disorientation $[3,11]$.

Engineering of bioartificial tendons (BATs) such as by embedding tenocytes or fibroblasts cells in a threedimensional (3D) matrix of type 1 collagen and simultaneous application of mechanical load increases expression of tendon-related genes such as Scleraxis $(S c x)$ and Type 1 collagen alpha 1 (Col1a1) with increasing strain [12]. The transcription factor Scx induces Tenomodulin (Tnmd), another important tendon-related marker mainly indicating differentiated and mature tenocytes [13]. Tnmo expression in mice Achilles tenocytes can be induced by $5 \%$ strain under $2 \mathrm{D}$ cultivation [14]. The transcription factor Mohawk $(M k x)$ is a further important tendon-related marker indicating tendon development $[15,16]$. Type 3 collagen alpha 1 (Col3a1) is a minor component in tendons in comparison to Colla1, but its ratio may change under load [1] or during tendinopathy [17]. Matrix metalloproteinases (e.g. Mmp3) are involved in extra cellular matrix (ECM) remodelling and may even have pro-inflammatory roles in tenocytes [18], which may be pronounced under inflammatory conditions [19] or overload conditions. Finally, a typical cytokine in tendons is interleukin IL-6 that is strongly increased under pro-inflammatory stimulation using 3D tendon-like constructs in vitro [19].

In this study, we use C3H10T1/2 cells, a murine cell line of mesenchymal stem cells that show a fibroblastic phenotype and are often used for engineering bioartificial tendons or similar 3D constructs [12, 20-22]. C3H10T1/2 cells possess the ability to differentiate into cell lineages related to the musculoskeletal system (e.g. chondrocytes, osteocytes, tenocytes) under certain mechanical cues rendering them an ideal system to study tendon differentiation under load [22]. We analyse tendon, ECM- and inflammation markers together with histological analyses to reveal if cyclic elongation of fibroblasts-laden BATs at overload (0-16\%) or physiological conditions $(0-8 \%)$ inhibits or favours tenogenic differentiation or inflammation, respectively.

\section{Materials and methods \\ Cell culture and BAT engineering}

Cells of the murine fibroblast cell line C3H10T1/2 (Clone 8, ATCC $^{\circ}$ CCL226 $^{\mathrm{m}}$, American Type Culture Collection, Manassas, VA) were propagated in DMEM/F12 culture medium (P04-41150, PAN-Biotech, Aidenbach, Germany) supplemented with 10\% FBS superior (fetal bovine serum, 0708G, Biochrom AG, Berlin, Germany) and $1 \%$ penicillin-streptomycin $\left(15140\right.$, $\mathrm{Gibco}^{\mathrm{Tx}}$, Fisher Scientific GmbH, Schwerte, Germany) in standard cell culture T-flasks by incubation at $37{ }^{\circ} \mathrm{C}$ and $5 \% \mathrm{CO}_{2}$; at $80 \%$ confluence cells were passaged. Cells were trypsinized using trypsin-EDTA $0.05 \%$ (25300054, Gibco $^{\mathrm{mix}}$ ) for $5 \mathrm{~min}$ at $37^{\circ} \mathrm{C}$, pelleted at $200 \mathrm{~g}$ for $5 \mathrm{~min}$ and seeded at a concentration of $1.5 \times 10^{5}$ per BAT. Therefore, cells were resuspended in $90 \mu \mathrm{l} \mathrm{PureCol}{ }^{\circ} \mathrm{EZ}$ gel type I collagen solution (5074-G, Advanced BioMatrix, San Diego, CA, USA), $45 \mu \mathrm{l}$ culture medium and $15 \mu \mathrm{l} \mathrm{FBS}$ and pipetted into each well of a linear type I collagen coated TissueTrain culture plate (TT-5001 C, FlexCell International, Hillsborough, NC, USA) in which a trough was applied by underpressure using the FX-6000 $\mathrm{T}^{\mathrm{Tx}}$ Tension System (FlexCell International). The construct was allowed to set for $2 \mathrm{~h}$, then covered with $3 \mathrm{ml}$ of culture medium and incubated for $7 \mathrm{~d}$ to form tendon-like structures; medium was changed every $48 \mathrm{~h}$. Each BAT construct was considered as an individual sample.

\section{Mechanical loading regime}

Uniaxial cyclic stretching on BATs was applied by sinusoidal elongation equating to $4 \%$ strain amplitude $(0-8 \%)$ i.e. physiological load, or $8 \%(0-16 \%)$ i.e. overload [both regimes are defined according to $[12,16,23]]$ for $2 \mathrm{~h}$ per day at $0.1 \mathrm{~Hz}$ (i.e. 720 cycles per day; Fig. S1) for a total of seven days. $0.1 \mathrm{~Hz}$ resembles the frequency used clinically in tendinopathy rehabilitation programs emphasizing slow, heavy loading [12]. Control BATs were unloaded, but were under tension between the two anchors of a plate (Fig. 1).

\section{Cell viability/cytotoxicity staining}

BATs were washed three times in $3 \mathrm{ml}$ Dulbecco's phosphate-buffered saline (DPBS, D8537, Sigma-Aldrich, St. Louis, MO, USA) for $3 \mathrm{~min}$ at room temperature (RT) in the culture well. The LIVE/DEAD ${ }^{\mathrm{Tm}}$ Viability/ Cytotoxicity Kit for mammalian cells (L3224, Invitrogen $^{\mathrm{nw}}$, Carlsbad, CA, USA) was used according to manufactures introductions. As additional control, BATs were 


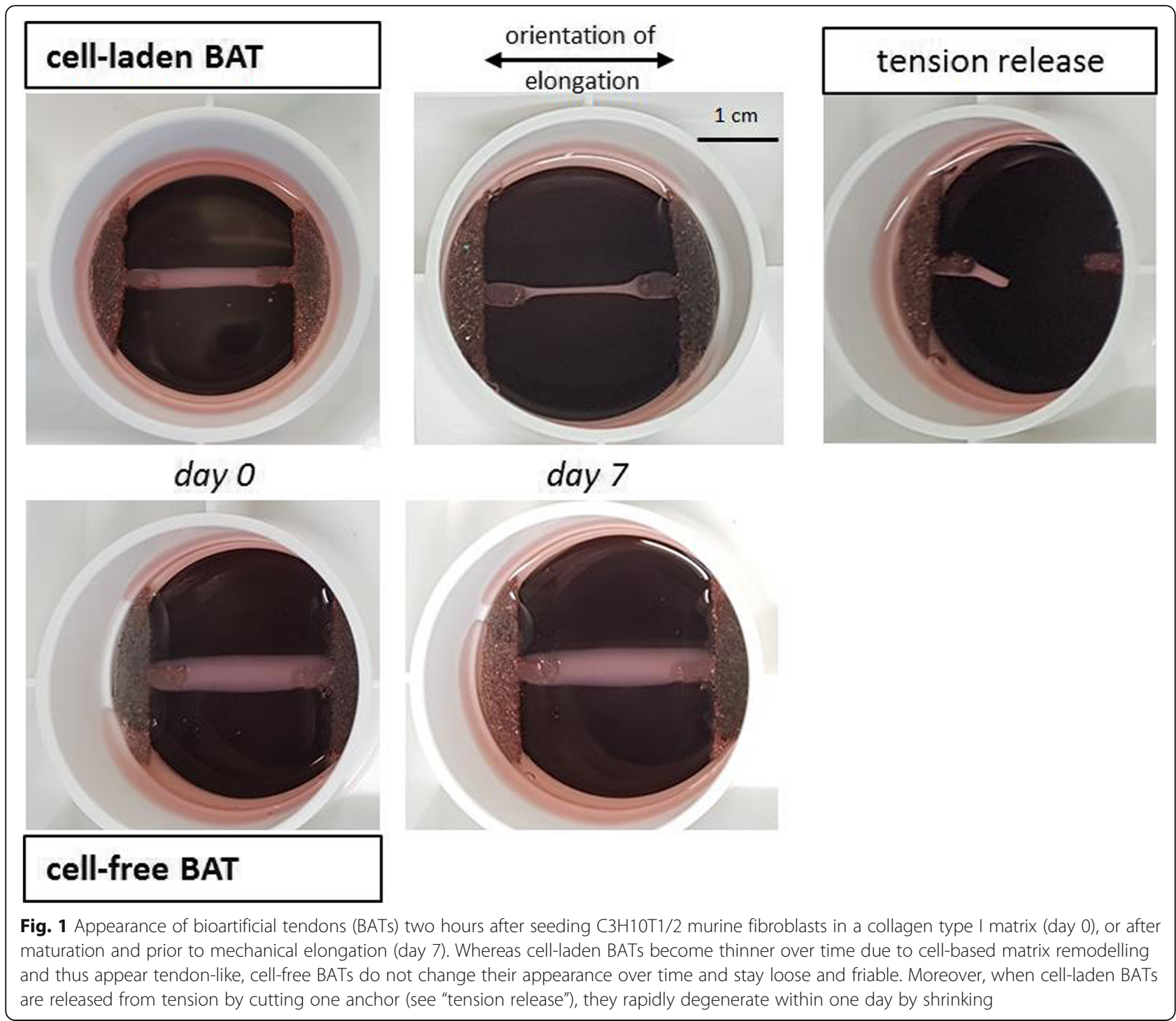

released from tension by cutting one anchor ("tension release"). Two $\mu \mathrm{l}$ ethidium homodimer-1 were mixed with $1 \mu \mathrm{l}$ calcein AM in $1 \mathrm{ml}$ DPBS and briefly vortexted. $100 \mu \mathrm{l}$ were added to one BAT placed on a microscopy slide and cover slip. After 15 min incubation at $\mathrm{RT}$ in the dark, cellular signals were visualised via fluorescence microscopy (AxioPlan 2 imaging, Zeiss, Jena, Germany) using according filter sets: calcein in green indicating viable cells (ex/em $490 \mathrm{~nm} / 515 \mathrm{~nm}$ ); ethidium homodimer-1 in red indicating dead cells (ex/em $560 \mathrm{~nm} / 630 \mathrm{~nm}$ ).

\section{Gene expression analysis}

Individual BATs were digested using collagenase $\mathrm{P}$ (1 mg/ml; 11213873001, Roche, Merck KGaA, Darmstadt, Germany) for $2 \mathrm{~h}$ at $37{ }^{\circ} \mathrm{C}$. Cells were pelleted by centrifugation at $200 \mathrm{~g}$ for $5 \mathrm{~min}$ at RT, supernatant was removed and cells were lysed using buffer RLT Plus from the RNeasy ${ }^{\circ}$ Plus Mini kit (74136, Qiagen, Hilden, Germany). For further RNA extraction the handbook's protocol "Purification of Total RNA from Animal Cells" was followed. Synthesis of cDNA was carried out using qScript $^{\oplus}$ cDNA SuperMix (95048-100, Quantabio, Beverly, MA, USA). Amplification reactions were set-up by mixing $5 \mu \mathrm{l} 2 \mathrm{xPerfeCTa}^{\circ}$ SYBR $^{\circ}$ Green SuperMix (95054-500, Quantabio) with $1 \mu$ l template cDNA (refers to 4 ng transcribed RNA) and primers (forward and reverse, final $10 \mu \mathrm{M}$ each) with nuclease-free water (129114, Qiagen) in a total of $10 \mu \mathrm{l}$. Primers for the following genes were used: the tenogenic markers $S c x$, Tnmd and Mkx; the ECM-related genes Colla1 and Col3a1 as well as the ECM-remodelling Mmp3 (sequences see Table S1). Amplification was monitored in real-time on a Rotor-Gene Q (Qiagen) and quantified using Glyceraldehyde 3-phosphate dehydrogenase (Gapdh) as the housekeeping gene. Normalised gene 
expression was calculated using a primer efficiency corrected equation [24] relative to the expression of unloaded control BATs.

\section{IL-6 cytokine quantification}

Enzyme-linked immunosorbent assays (Elisa) targeting the proinflammatory cytokine IL-6 (Mouse IL-6 ELISA Kit, RAB0308, Sigma-Aldrich) were conducted using centrifuged $\left(10,000 \mathrm{~g}\right.$ for $10 \mathrm{~min}$ at $\left.4{ }^{\circ} \mathrm{C}\right)$ supernatant of cell culture medium from BATs. IL-6 concentration in $100 \mu \mathrm{l}$ undiluted supernatant of individual BATs were measured in $\mathrm{pg} / \mathrm{ml}$. For quantification, values were normalised to unloaded controls.

\section{Hematoxylin and eosin staining}

BATs were fixed in $4 \%$ paraformaldehyde/DPBS at $5{ }^{\circ} \mathrm{C}$ overnight in dark conditions followed by three washing steps in each $0.4 \%$ paraformaldehyde/DPBS and DPBS. Fixed BATs were embedded in paraffin blocks and sectioned into $5 \mu \mathrm{m}$ thin longitudinal slices using rotary microtome RM2265 (Leica, Wetzlar, Germany). After dewaxing and rehydrating using graded alcohol, specimens were stained for $8 \mathrm{~min}$ in Mayers hemalum solution (109249, Merck) followed by rinsing with tap water for $10 \mathrm{~min}$. Slides were immersed in $0.1 \%$ eosin G (C.I. 45380) solution (115935, Merck) for $5 \mathrm{~min}$. Slices were dehydrated in an ascending alcohol and immersed two times in xylol for $3 \mathrm{~min}$. Finally, coverslips were mounted on top of the slides after adding Histofluid (6900002, Marienfeld GmbH, Lauda-Königshofen, Germany). After drying overnight at RT, H\&E stained specimens were scanned using NanoZoomer 2.0-HT (Hamamatsu Photonics, Shizuoka, Japan). The Fiji software tool "analyse particles" was used for image analysis [25] measuring nuclear roundness, area and cellular density.

\section{F-actin staining}

Fixed BATs were used for visualisation of the cytoskeleton by F-actin staining. BATs were washed three times for 5 min by gentle agitation at RT in DPBS followed by incubation for $1 \mathrm{~h}$ at RT with 1x Phalloidin-iFluor 488 Reagent (ab176753, abcam, Cambridge, UK) in DPBS/1\% BSA including nuclear counter-stain Hoechst 34580 $\left(\mathrm{H} 21486\right.$, Invitrogen $\left.{ }^{\mathrm{Tw}}\right)$ at final concentration of $1 \mu \mathrm{g} / \mathrm{ml}$. After three wash steps in DPBS, BATs were placed on top of a slide and mounted with ProLong ${ }^{\text {mex }}$ gold antifade (P36934, Invitrogen ${ }^{\mathrm{m}}$ ) under a cover slip. Fluorescent cells in BATs were visualized by confocal laser scanning microscopy (LSM 710, Zeiss, Jena, Germany) using a $40 \times / 1.2$ C-Apochromat $^{\oplus}$ (Zeiss) for magnification. Excitation was conducted through a $405 \mathrm{~nm}$ laser diode and a $488 \mathrm{~nm}$ argon laser (Zeiss). The systems spectral Quasar detector was set up to monitor specimens at 415-
$490 \mathrm{~nm}$ for Hoechst and 490-561 nm for Phalloidinlabelled probes. Maximum intensity projection of $\mathrm{z}$ stacks was used and images were processed using the imaging software ZEN (Zeiss).

\section{Statistics and sample size}

Multiple group comparisons (i.e. overload versus physiological load versus controls for gene expression or Elisa) were calculated by using Kruskal-Wallis test with Dunn's multiple comparison followed by Bonferroni-HolmCorrection. Statistical differences between BATs subjected to overload versus physiological load with respect to nuclear roundness, area and density were additionally calculated using Mann-Whitney U-test. In all cases SPSS 26 (IBM) was used to calculate statistics. For samples sizes, see Table $\mathrm{S} 2$.

\section{Results}

\section{Cell viability}

The majority of cells in overloaded, physiologically loaded and unloaded control BATs were positive for calcein green fluorescent staining which indicates viable cells (Fig. 2). Few cells were positive for ethidium homodimer-1 red fluorescent staining indicating dead cells. However, there were no obvious differences in cell survival and viability between overloaded, physiologically loaded and unloaded BATs, i.e. most cells survived two weeks in BATs including one week maturation followed by another week under mechanical load. However, cells in tension-released BATs showed a lower ratio of live to dead cells compared to loaded or control BATs (Fig. 2).

\section{Gene expression}

Expression of tenogenic marker genes such as $S c x$, Tnmd and $M k x$ (Fig. 3A) as well as the ECM-related collagen genes Colla1 and Col3a1 (Fig. 3B) were significantly decreased in BATs subjected to overload ( $\varnothing 8 \%$ elongation) compared to physiological load (ø 4\%) and unloaded controls $(0 \%$, yet under tension), respectively. $M k x$ and Tnmd were significantly increased in BATs subjected to physiological load compared to controls. In contrast, expression of $M m p 3$ was significantly increased at overload compared to physiological load, but significantly decreased under physiological load compared to unloaded controls.

\section{IL-6 quantification}

Levels of IL-6 in culture supernatants of fibroblastsladen BATs subjected to mechanical overload were similar (median 2.02; interquartile range 1.06) to BATs subjected physiological load (median 1.63; interquartile range 0.40) (Fig. 4). In both cases, IL-6 levels were significantly higher under overload or physiological load compared to unloaded controls $(p=0.004 ; p=0.007)$. 

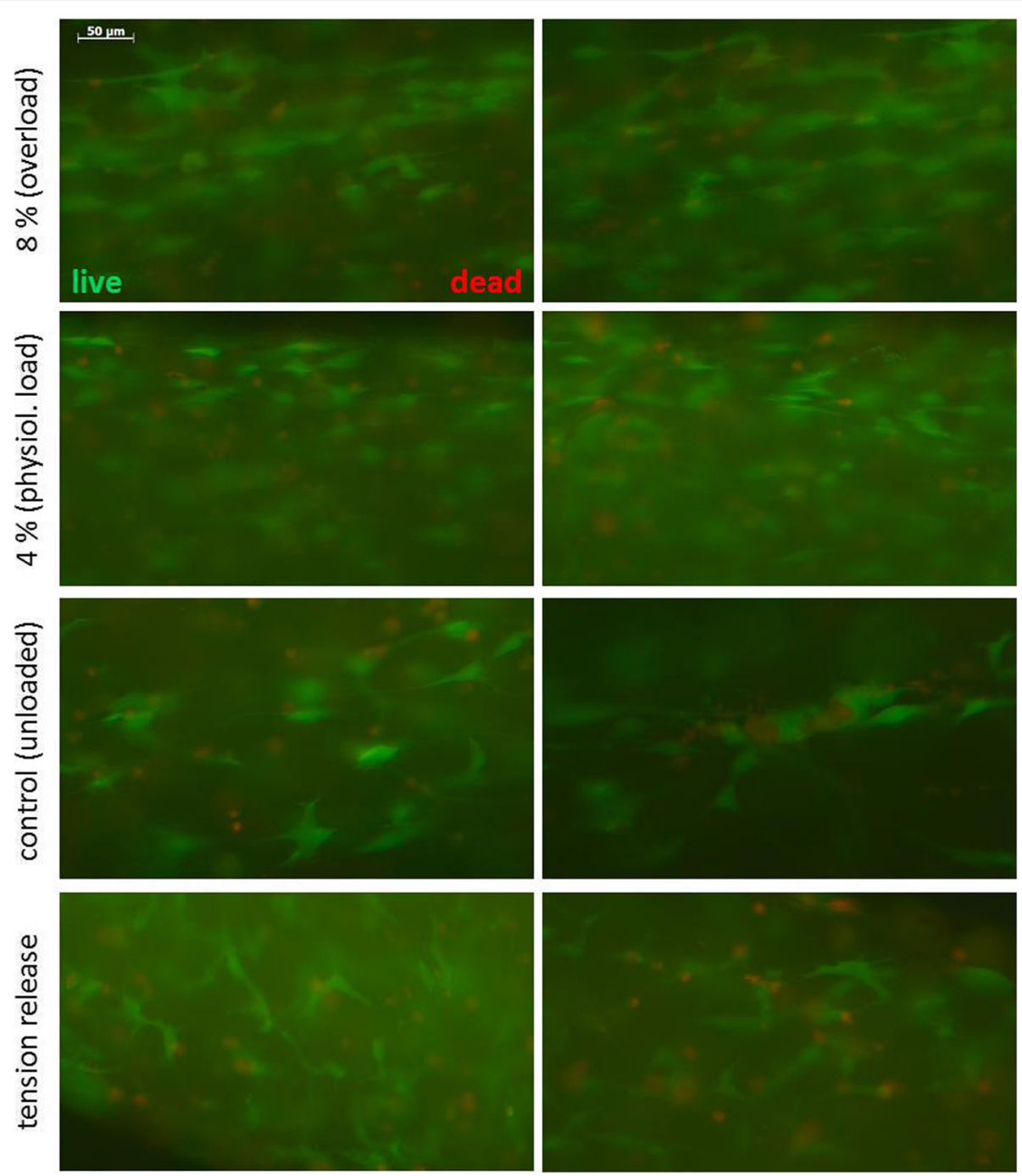

Fig. 2 Cell survival in BATs after one week of maturation without load and another week with cyclic elongation at overload conditions (mean 8\%) or physiological load (mean 4\%) as well as unloaded controls and tension-released BATs. Three BATs of each treatment were stained with calcein AM (green fluorescent, viable cells) and ethidium homodimer-1 (red fluorescent, dead cells) to distinguish green live and red dead cells via fluorescence microscopy. There was no obvious difference in the ratio of live to dead cells among the treatments and most cells were alive. Only cells in tension-released BATs showed a lower ratio of live to dead cells compared to loaded or control BATs

\section{Histology}

H\&E staining of longitudinal sections of BATs showed a relative uniform distribution of $\mathrm{C} 3 \mathrm{H} 10 \mathrm{~T} 1 / 2$ cells along the constructs (Fig. 5A). Longitudinal alignment of cells in strain direction with numerous cell-to-cell contacts was especially pronounced in BATs subjected to physiological load, whereas orientation of cells in control BATs appeared more randomly (Fig. 5A, B). Nuclear area ( $p=$ $0.222)$ and roundness of nuclei $(p=0.548)$ were not different between physiological and overload conditions (Fig. 5C). Cellular density did not differ significantly between overload and physiological load $(p=0.095)$ (Fig. 5C).

\section{Discussion}

Various cell types embedded in 3D tendon-like constructs are able to respond to physiological load, mainly with enhanced expression of tendon-related markers, elongated cell shape and increased cellular alignment (reviewed in 1, 5, 6). This knowledge is confirmed in our study using fibroblasts-laden BATs. However, only few studies have analysed the impact of overload on 3Dcultered tenocytes or fibroblasts e.g. [26]. Using latter cell type seeded in BATs, here we show that mechanical overload decreases molecular and histological tendonrelated markers, whereas physiological load increases tenogenesis. 


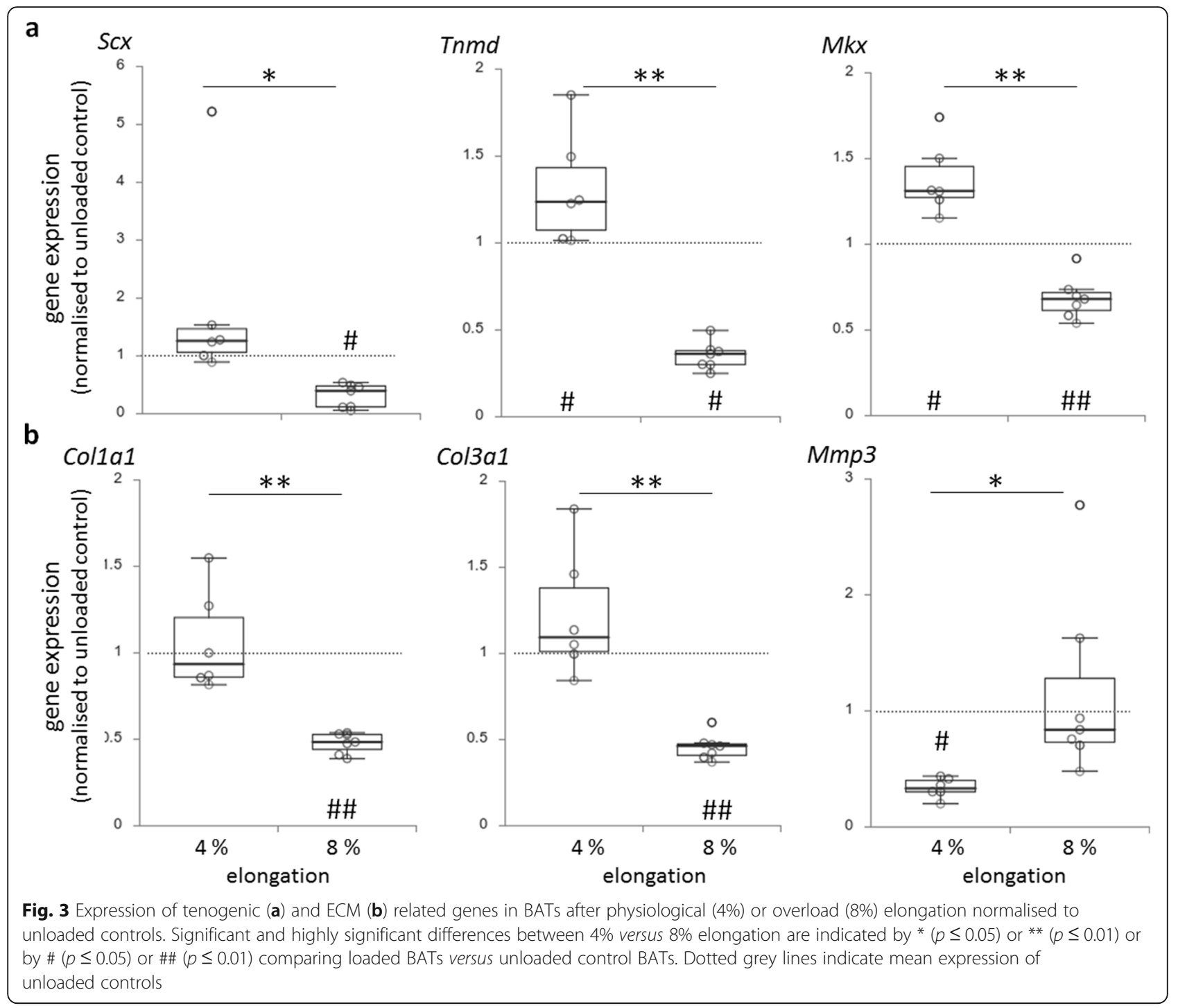

Load, or at least tension, is essential for maturation and functioning of fibroblasts-laden BATs as shown in this study, since tension-released BATs quickly degenerated and shrank (Fig. 1). Similarly, 3D constructs using C3H10T1/2 fibroblasts showed decreased expression of the tendon-related genes $S c x$, Tnmd and Colla1 after tension release in comparison to constructs under tension [27]. Moreover, whereas cell-free BATs stayed loose and friable over time since they lack the ability of fibroblasts to remodel the matrix, cell-laden BATs acquired a thin, solid and tendon-like phenotype within one week when under tension (Fig. 1); this is consistent with findings from other studies using BATs [12, 28].

Survival of cells in 3D constructs over a longer time seems to require load or at least tension. Comparable cell survival was found for C3H10T1/2 cells after 15 days of culture or mechanical load [21]. This is similar to our findings showing that cell survival and viability did not differ among physiological, overload and unloaded controls (Fig. 2). Similarly, cyclic strain at different frequencies $(0.3,0.5,1.0 \mathrm{~Hz})$ and amplitudes $(2,4$, 8\%) subjected to Achilles tendon-derived stem cells (TDSCs) from rats in a 3D-bioreactor had no influence on their viability [29].

However, when BATs were subjected to overload (up to $16 \%$ ) tenogenesis, i.e. expression of $S c x$, Tnmd, $M k x$, Colla1 and Col3a1, was significantly decreased compared with a lower, physiological load (up to $8 \%$ ) or unloaded controls (Fig. 3). Alike, Achilles TDSCs from rats that were cyclically stretched at $2 \%, 4 \%$ or $8 \%$ showed highest expression of Col1a1, Tnmd and Scx at intermediate $4 \%$ strain [29]. Interestingly, straining human mesenchymal stem cells cyclically at $10 \%$ or statically at $15 \%$ in 3D scaffolds resulted in upregulation of Scx, Tnmd and Colla1 [30, 31]. Moreover, the expression of Mmp3, a protein important for ECM 


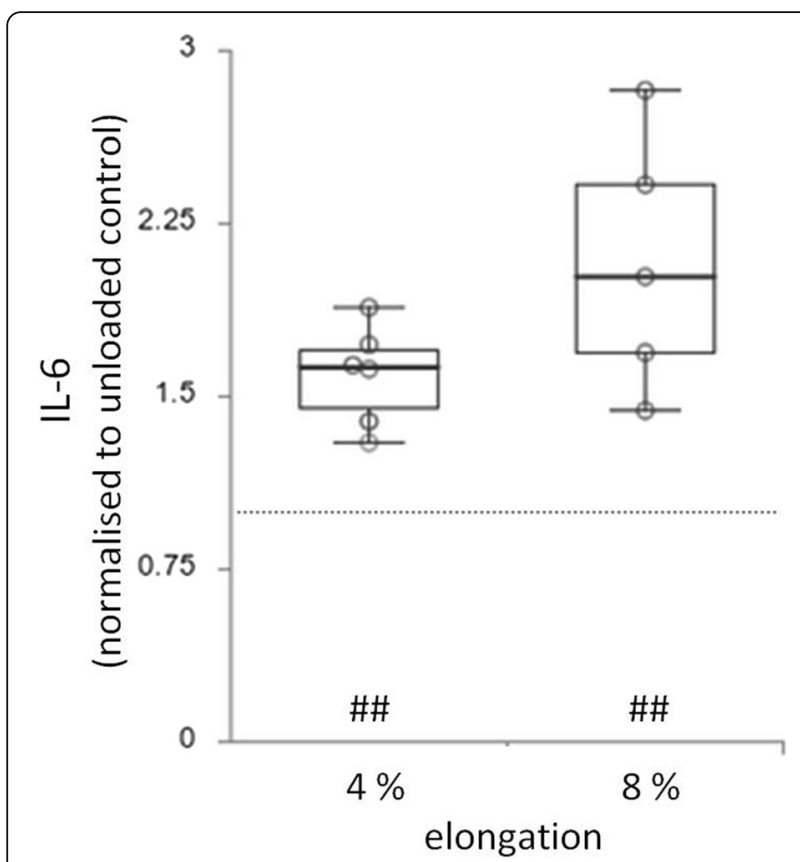

Fig. 4 Quantification of interleukin-6 in cell culture supernatant of BATs subjected to physiological (4\%) or overload (8\%) elongation after normalisation to unloaded controls. Significant differences between loaded BATs versus unloaded controls are indicated by \#\# $(p \leq 0.01)$. Dotted grey line indicates mean IL-6 level of unloaded controls

remodelling, was increased in BATs subjected to overload compared to physiological load, while physiological load resulted in a reduced expression compared to static conditions (Fig. 3). Quantification of IL-6 in the supernatant revealed an increase due to load (both over and physiological) compared to static controls (Fig. 4). Using rodent TDSCs in 3D tendon-like constructs under proinflammatory stimulation (yet unloaded) resulted in increased expression of Mmp3 and IL-6, whereas Col1a1, Col3a1, Scx, Tnmd and Mkx expression did not change compared to untreated controls [19]. However, as shown in our study, these genes responded to mechanical load, i.e. decreased by overload and increased by physiological load (Fig. 3). Further studies confirm that improper loading can induce expression of anabolic and catabolic genes. For example, rabbit Achilles tendons cultured ex vivo showed highest Mmp3 expression at 3\% (underloaded), whereas Colla1 and Col3a1 expression were highest at $6 \%$ or $9 \%$ strain (overload), respectively [3]. In parallel cell apoptosis and collagen disorientation occurred at $9 \%$ overload, whereas $6 \%$ strain maintained the structural integrity and cellular function best [3]. Similarly, loading of rat tenocytes at $15 \%$ induced cytoskeleton damage due to F-actin depolymerisation [32]. Thus, mechanical overload does not only induce gene expression changes, but can also lead to morphological changes. This is confirmed in our study, since fibroblasts in BATs subjected to overload had reduced nuclear area, probably due to a more rounded and less elongated shape compared to cells subjected to physiological load (Fig. 5). Even though the changes were not significant, they are similar to the changes seen in tendinopathic tissue. Longer stimulation periods might result in more pronounced alterations as tendinopathy is also a result of a longer alteration process.

Physiological load as used here increased tenogenic differentiation in comparison to mainly overload, but also to unloaded conditions (Fig. 3). This result confirms findings from other studies. For example, using fibroblasts-laden BATs strained with a comparable regime as ours $(0.1 \mathrm{~Hz}$ for $2 \mathrm{~h} / \mathrm{d})$ at $5-10 \%$, Scott et al. [12] showed an increased expression of Scx and Colla1 especially under cyclic compared to static load. Using the same fibroblasts in a 3D fibrinogen gel subjected to $10 \%$ cyclic load ( $1 \mathrm{~h}$ per day at $0.5 \mathrm{~Hz}, 15 \mathrm{~d}$ total), Col1a1 expression was significantly increased [21]. Fibroblasts in BATs subjected to physiological load were also found to have minor changes in cellular morphology, e.g. an alignment of the cytoskeleton in strain direction (Fig. 5B, C). Other studies found in descriptive histological analysis that loaded fibroblasts or tenocytes have well-aligned cytoskeletal organization and elongated nuclei, whereas unloaded cells were more rounded and poorly differentiated [12, 21, 28, 33, 34]. Using quantitative analysis, we assessed comparable differences and alterations due to different loading conditions, even though the differences reached not significant values. Interestingly, cyclic overload at $15 \%$ but at higher frequency $(1 \mathrm{~Hz})$ as used in our study exerted a proinflammatory effect in rat Achilles tenocytes, mainly due to disruption of the cytoskeleton, which may also contribute to tendinopathy [32].

Future research about the impact of overload on (bioartificial) tendons should take into account that physiologic load of individual tendons differ among their function, age, sex, location and species [9]. Given the high worldwide prevalence of tendon injuries such as tendinopathies and the limited self-renewal capacity of tendons [35], it is of clinical importance to avoid potentially harmful overload movements that may occur during rehabilitation programs [36]. These challenges could be faced through an stepwise expansion of the current study by: (i) using BATs seeded with primary cells such as tenocytes or TDSCs preferably from humans to overcome potential limitations of a murine cell line [e.g. they are not preferentially committed to the tendon lineage as compared to TDSCs originating from native tissues, they may differentiate into other cells of the 


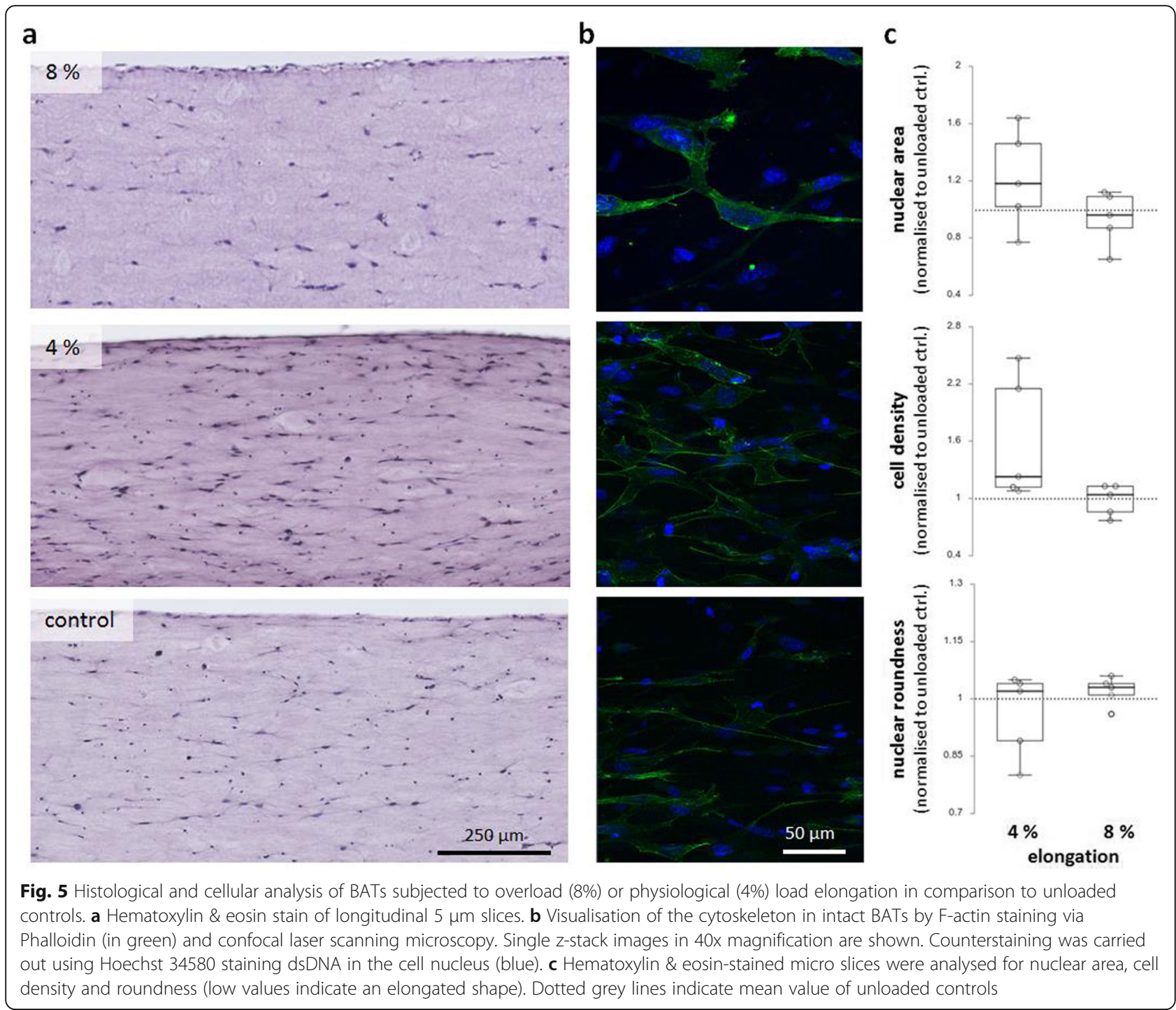

musculoskeletal system [22]], (ii) analysing the impact of further mechanostimulation variables such as frequency, duration or rest insertion in addition to amplitude, and (iii) straining ex vivo or genetically modified in vivo tendon models $[37,38]$ at overload.

\section{Conclusions}

We mainly found that mechanical overload decreases gene expression of tendon-related markers and collagens, whereas expression of remodelling/inflammation markers increased. In contrast, physiological load increased expression of tendon-related markers in BATs and was accompanied by histological changes such as aligned cells in strain direction - an important marker also found in native tendon tissue [39]. Thus, our overload results show some potential parallels to tendinopathy, a tendon disease condition at which cell alignment and elongated morphology are lost and inflammatory and ECM remodelling marker genes are increased [40].

\section{Supplementary information}

The online version contains supplementary material available at https://doi. org/10.1186/s13036-022-00283-y.

\section{Additional file 1}

\section{Acknowledgements}

We thank Prof. Dr. Uta Dahmen und Ana Lucia Paz Hernandez from Experimental Transplantation Surgery at Jena University Hospital for conducting digital scans of our H\&E stains using NanoZoomer. We also acknowledge Birgit Lemser for her technical support.

\section{Authors' contributions}

Stefan Pentzold contributed conceptualization, methodology, validation, formal analysis, investigation, writing original draft and visualisation. Britt Wildemann contributed conceptualization, resources, writing review and editing, supervision and funding acquisition. The authors read and approved the final manuscript. 


\section{Funding}

The study was supported by internal funding from Jena University Hospital. Open Access funding enabled and organized by Projekt DEAL.

\section{Availability of data and materials}

The datasets used and/or analysed during the current study are available from the corresponding author on reasonable request.

\section{Declarations}

\section{Ethics approval and consent to participate}

Not applicable.

\section{Consent for publication}

Not applicable.

\section{Competing interests}

The authors declare no conflicts of interest regarding this article.

Received: 6 September 2021 Accepted: 10 February 2022

Published online: 03 March 2022

\section{References}

1. Sheng R, Jiang Y, Backman L, Zhang W, Chen J. The Application of Mechanical Stimulations in Tendon Tissue Engineering. Stem Cells Int. 2020; 2020:8824783

2. Galloway MT, Lalley AL, Shearn JT. The role of mechanical loading in tendon development, maintenance, injury, and repair. J Bone Joint Surg Am. 2013; 95(17):1620-8

3. Wang T, Lin Z, Day RE, Gardiner B, Landao-Bassonga E, Rubenson J, et al. Programmable mechanical stimulation influences tendon homeostasis in a bioreactor system. Biotechnol Bioeng. 2013;110(5):1495-507.

4. Li HY, Hua YH. Achilles Tendinopathy: Current Concepts about the Basic Science and Clinical Treatments. Biomed Res Int. 2016;2016:6492597.

5. Citeroni MR, Ciardulli MC, Russo V, Della Porta G, Mauro A, El Khatib M, et al. In vitro innovation of tendon tissue engineering strategies. Int J Mol Sci. 2020;21(18):6726.

6. Jaiswal D, Yousman LC, Neary M, Fernschild E, Zolnoski B, Katebifar S, et al. Tendon tissue engineering: biomechanical considerations. Biomed Mater. 2020;15(5):052001.

7. Qi F, Deng Z, Ma Y, Wang S, Liu C, Lyu F, et al. From the perspective of embryonic tendon development: various cells applied to tendon tissue engineering. Ann Transl Med. 2020;8(4):131.

8. Chen $\mathrm{J}$, Zhang W, Liu ZY, Heng BC, Ouyang HW, Dai XS. Physical regulation of stem cells differentiation into teno-lineage: current strategies and future direction. Cell Tissue Res. 2015:360(2):195-207.

9. Lavagnino M, Wall ME, Little D, Banes AJ, Guilak F, Arnoczky SP. Tendon mechanobiology: Current knowledge and future research opportunities. J Orthop Res. 2015;33(6):813-22.

10. Chen W, Deng Y, Zhang J, Tang K. Uniaxial repetitive mechanical overloading induces influx of extracellular calcium and cytoskeleton disruption in human tenocytes. Cell Tissue Res. 2015;359(2):577-87.

11. Jiang $Y$, Liu H, Li H, Wang F, Cheng K, Zhou G, et al. A proteomic analysis of engineered tendon formation under dynamic mechanical loading in vitro. Biomaterials. 2011:32(17):4085-95.

12. Scott A, Danielson P, Abraham T, Fong G, Sampaio A, Underhill T. Mechanical force modulates scleraxis expression in bioartificial tendons. J Musculoskelet Neuronal Interact. 2011;11(2):124-32.

13. Shukunami C, Takimoto A, Nishizaki Y, Yoshimoto Y, Tanaka S, Miura S, et al. Scleraxis is a transcriptional activator that regulates the expression of Tenomodulin, a marker of mature tenocytes and ligamentocytes. Sci Rep. 2018;8(1):3155

14. Kubo Y, Hoffmann B, Goltz K, Schnakenberg U, Jahr H, Merkel R, et al. Different Frequency of Cyclic Tensile Strain Relates to Anabolic/Catabolic Conditions Consistent with Immunohistochemical Staining Intensity in Tenocytes. Int J Mol Sci. 2020;21(3):1082.

15. Ito Y, Toriuchi N, Yoshitaka T, Ueno-Kudoh H, Sato T, Yokoyama S, et al. The Mohawk homeobox gene is a critical regulator of tendon differentiation. Proc Natl Acad Sci USA. 2010;107(23):10538-42.
16. Yang F, Zhang A, Richardson DW. Regulation of the tenogenic gene expression in equine tenocyte-derived induced pluripotent stem cells by mechanical loading and Mohawk. Stem Cell Res. 2019;39:101489.

17. Millar NL, Silbernagel KG, Thorborg K, Kirwan PD, Galatz LM, Abrams GD, et al. Tendinopathy Nat Rev Dis Prim. 2021;7(1):1.

18. Tsuzaki M, Guyton G, Garrett W, Archambault JM, Herzog W, Almekinders L, et al. IL-1 $\beta$ induces COX2, MMP-1, -3 and - 13, ADAMTS-4, IL-1 $\beta$ and IL-6 in human tendon cells. J Orthop Res. 2003;21(2):256-64.

19. Lehner C, Spitzer G, Gehwolf R, Wagner A, Weissenbacher N, Deininger C, et al. Tenophages: a novel macrophage-like tendon cell population expressing CX3CL1 and CX3CR1. Dis Model Mech. 2019;12(12):dmm041384.

20. Mousavizadeh R, Hojabrpour P, Eltit F, McDonald PC, Dedhar S, McCormack $R G$, et al. beta1 integrin, ILK and mTOR regulate collagen synthesis in mechanically loaded tendon cells. Sci Rep. 2020;10(1):12644.

21. Testa S, Costantini M, Fornetti E, Bernardini S, Trombetta M, Seliktar D, et al. Combination of biochemical and mechanical cues for tendon tissue engineering. J Cell Mol Med. 2017;21(11):2711-9.

22. Gaut L, Bonnin MA, Blavet C, Cacciapuoti I, Orpel M, Mericskay M, et al. Mechanical and molecular parameters that influence the tendon differentiation potential of C3H10T1/2 cells in 2D- and 3D-culture systems. Biology Open. 2020:9(2):bio047928.

23. Wang $T$, Chen $P$, Zheng $M$, Wang A, Lloyd $D$, Leys $T$, et al. In vitro loading models for tendon mechanobiology. J Orthop Res. 2018;36(2):566-75.

24. Rao X, Huang X, Zhou Z, Lin X. An improvement of the 2^ (-delta delta CT) method for quantitative real-time polymerase chain reaction data analysis. Biostat bioinf biomath. 2013;3(3):71.

25. Schindelin J, Arganda-Carreras I, Frise E, Kaynig V, Longair M, Pietzsch T, et al. Fiji: an open-source platform for biological-image analysis. Nat Methods. 2012;9(7):676-82.

26. Zhang J, Wang JH. The effects of mechanical loading on tendons-an in vivo and in vitro model study. PLoS ONE. 2013;8(8):e71740.

27. Gaut L, Robert N, Delalande A, Bonnin MA, Pichon C, Duprez D. EGR1 Regulates Transcription Downstream of Mechanical Signals during Tendon Formation and Healing. PLoS ONE. 2016;11(11):e0166237.

28. Garvin J, Qi J, Maloney M, Banes AJ. Novel system for engineering bioartificial tendons and application of mechanical load. Tissue Eng. 2003; 9(5):967-79

29. Xu Y, Wang Q, Li Y, Gan Y, Li P, Li S, et al. Cyclic Tensile Strain Induces Tenogenic Differentiation of Tendon-Derived Stem Cells in Bioreactor Culture. Biomed Res Int. 2015:2015:790804.

30. Rinoldi C, Fallahi A, Yazdi IK, Campos Paras J, Kijeńska-Gawrońska E, Trujillode Santiago G, et al. Mechanical and Biochemical Stimulation of 3D Multilayered Scaffolds for Tendon Tissue Engineering. ACS Biomater Sci Eng. 2019:5(6):2953-64.

31. Rinoldi C, Costantini M, Kijeńska-Gawrońska E, Testa S, Fornetti E, Heljak M, et al. Tendon tissue engineering: Effects of mechanical and biochemical stimulation on stem cell alignment on cell-laden hydrogel yarns. Adv Healthc Mat. 2019;8(7):1801218

32. Chen Q, Zhou J, Zhang B, Chen Z, Luo Q, Song G. Cyclic stretching exacerbates tendinitis by enhancing NLRP3 inflammasome activity via Factin depolymerization. Inflammation. 2018;41(5):1731-43.

33. Sawadkar P, Player D, Bozec L, Mudera V. The mechanobiology of tendon fibroblasts under static and uniaxial cyclic load in a 3D tissue engineered model mimicking native extracellular matrix. J Tissue Eng Regen Med. 2020; 14(1):135-46.

34. Wang T, Thien C, Wang C, Ni M, Gao J, Wang A, et al. 3D uniaxial mechanical stimulation induces tenogenic differentiation of tendon-derived stem cells through a PI3KVAKT signaling pathway. FASEB J. 2018;32(9):480414.

35. Nourissat G, Berenbaum F, Duprez D. Tendon injury: from biology to tendon repair. Nat Rev Rheumatol. 2015;11(4):223-33.

36. Freedman BR, Gordon JA, Soslowsky LJ. The Achilles tendon: fundamental properties and mechanisms governing healing. Muscles Ligaments Tendons J. 2014;4(2):245.

37. Wunderli SL, Widmer J, Amrein N, Foolen J, Silvan U, Leupin O, et al. Minimal mechanical load and tissue culture conditions preserve native cell phenotype and morphology in tendon-a novel ex vivo mouse explant model. J Orthop Res. 2018;36(5):1383-90.

38. Zhang J, Nie D, Williamson K, McDowell A, Hogan MV, Wang JH. Moderate and intensive mechanical loading differentially modulate the phenotype of tendon stem/progenitor cells in vivo. PLoS ONE. 2020;15(12):e0242640. 
39. Gracey E, Burssens A, Cambre I, Schett G, Lories R, Mclnnes IB, et al. Tendon and ligament mechanical loading in the pathogenesis of inflammatory arthritis. Nat Rev Rheumatol. 2020;16(4):193-207.

40. Ackermann PW, Renström P. Tendinopathy in sport. Sports Health. 2012;4(3): 193-201.

\section{Publisher's Note}

Springer Nature remains neutral with regard to jurisdictional claims in published maps and institutional affiliations.

Ready to submit your research? Choose BMC and benefit from:

- fast, convenient online submission

- thorough peer review by experienced researchers in your field

- rapid publication on acceptance

- support for research data, including large and complex data types

- gold Open Access which fosters wider collaboration and increased citations

- maximum visibility for your research: over $100 \mathrm{M}$ website views per year

At $\mathrm{BMC}$, research is always in progress.

Learn more biomedcentral.com/submissions 